\title{
Ensino e Pesquisa em Defesa no Brasil: Estruturação do Campo e Desafios
}

\section{Teaching and Research on Defense in Brazil: Field Structuring and Challenges}

Rev. Bra. Est. Def. v. 2, nº 2, jul./dez. 2015, p. 57-73

ISSN 2358-3932

ADRIANA A. MARQUES

ALEXANDRE FUCCILLE

\section{INTRODUÇÃO}

O processo de institucionalização dos Estudos de Defesa nas universidades brasileiras é bastante recente. Os primeiros Programas de Pós-Graduação com área de concentração em assuntos de Defesa foram criados nos anos 2000. O primeiro curso de graduação em Defesa começou a funcionar na Universidade Federal do Rio de Janeiro (UFRJ) em 2010. No entanto, a gênese do que hoje se convencionou chamar Estudos de Defesa remonta há algumas décadas quando um pequeno grupo de jovens pesquisadores - oriundos da Ciência Política, em sua maioria - começou a estudar de forma sistemática o aparelho militar brasileiro, suas especificidades, comportamento e padrão de relacionamento com o sistema político nacional.

Neste artigo iremos delinear a trajetória dos Estudos de Defesa no Brasil, começando com um breve panorama das percepções da intelectualidade brasileira sobre as Forças Armadas - em especial dos cientistas sociais nas décadas de 1960 e 1970 -, passando então à identificação dos primeiros estudos que impulsionaram a configuração do campo e algumas iniciativas mais estruturadas que deram suporte ao seu crescimento ao longo das décadas para, em seguida, acompanharmos as mudanças estruturais nos contextos políticos internacional, nacional e regional na década de 1990 e suas conexões com o ambiente acadêmico da Ciência Política e

Alexandre Fuccille - Doutor em Ciência Política (Unicamp) e professor de Relações Internacionais (UNESP). E-mail: fuccille@hotmail.com

Adriana A. Marques - Doutora em Ciência Política (USP) e professora de Defesa (UFRJ). E-mail: adri-marques@uol.com.br 
das Relações Internacionais no Brasil. Também detalharemos a estruturação de linhas de pesquisa em Defesa nos Programas de Pós-Graduação a partir da criação de editais de fomento à pesquisa, voltados especificamente para o campo e, por fim, abordaremos o processo de criação da Associação Brasileira de Estudos de Defesa (ABED) e os desafios colocados para o campo de estudos nos próximos anos.

\section{A PESQUISA SOBRE OS MILITARES DURANTE A DITADURA (1964-1985)}

As décadas de 1960 e 1970 na América Latina foram marcadas por uma sucessão de golpes militares que mudaram drasticamente o panorama político e social do continente. No Brasil, os militares tomaram diretamente o poder em 1964 e, rompendo um padrão de comportamento centenário, permaneceram no governo por duas décadas. É importante sublinhar que apesar de sua evidente importância histórica e peso político, as Forças Armadas não mereceriam a devida atenção da academia brasileira até o golpe de 1964. A quebra de padrão no comportamento dos militares, que ao invés de derrubarem o governo João Goulart e respaldarem a realização de novas eleições em 1966 (como esperava a elite política que havia batido às portas dos quartéis, como tantas outras vezes, em busca de um arbítrio para suas disputas), decidiram se manter no poder e fechar progressivamente o regime, colocou alguns condicionantes políticos e acadêmicos para os estudiosos brasileiros.

Do ponto de vista político, estudar a caserna durante a ditadura tornou-se um empreendimento perigoso e complicado, haja vista que o foco dos estudos poderia recair sobre a Doutrina de Segurança Nacional (DSN), os chamados Partidos Militares, o Estado Militar, etc. Perigoso porque o fechamento cada vez maior do regime dificultava sobremaneira a tarefa de quem se propusesse a realizar uma pesquisa sobre a instituição que ocupava o poder e complicado porque se o risco de ser considerado um inimigo do regime a procura de informações que pudessem derrotá-lo era grande (e trazia riscos a própria integridade física), havia a possibilidade, igualmente ampla, de ser identificado como simpatizante do regime, o que também prejudicaria a carreira, especialmente nas Ciências Sociais, que se constituíram em um foco importante de resistência ao autoritarismo.

Havia ainda um problema acadêmico que turvava a visão de quem se propusesse a refletir sobre por que os militares não haviam devolvido o poder aos civis, como sempre haviam feito até então, pois a escassa bibliografia existente sobre as Forças Armadas brasileiras tendia a posicionar os militares na dinâmica das classes sociais. Dentro deste modelo explicativo, havia a tese marxista clássica para o golpe de 1964, segundo a qual os militares 
seriam um instrumento da classe dominante, que teria abdicado de exercer o poder diretamente, em um momento Brumário (Moraes, 1987). Mas era especialmente forte entre a intelectualidade brasileira a tese de que os militares seriam representantes das "classes médias" e agiriam de acordo com os interesses desta parcela da população. ${ }^{1}$ Esta tese, mais otimista em sua origem, uma vez que os militares eram vistos como um setor progressista e modernizador que se contrapunha à elite política e econômica conservadora, foi perdendo sua capacidade explicativa à medida que o regime foi se fechando e a oposição a ele foi crescendo nas camadas médias urbanas.

Para compreender melhor a força das ideias apresentadas acima, faz-se necessário clarificar o contexto em que estes debates acadêmicos ocorriam. O sistema universitário brasileiro nas décadas de 1960 e 1970 era pequeno e altamente concentrado na região sudeste, mais especificamente no eixo Rio-São Paulo, no que concerne às Ciências Sociais. Em São Paulo, na USP e mais tarde na Unicamp, que criou seu mestrado em Ciência Política em 1974, a influência do estruturalismo francês e do marxismo era bastante proeminente, e reforçava a percepção reinante nestes centros de pensamento de que a ação política das Forças Armadas nada mais era do que um epifenômeno da luta de classes no Brasil.

É importante lembrar que neste período não haviam núcleos, centros de pesquisa dedicados ao estudo das Forças Armadas brasileiras, havendo apenas algumas iniciativas isoladas que buscavam dar conta da nova realidade política do país, o que exigia uma reflexão mais sistematizada sobre a instituição que estava no poder. Um exemplo bastante significativo destas iniciativas pode ser encontrado na coleção História Geral da Civilização Brasileira, coordenada por Sérgio Buarque de Holanda, um dos pensadores mais expressivos na história das Ciências Sociais no Brasil. A coleção abrange toda a história de nosso país do período colonial até 1964, e conta com dois capítulos do próprio Sérgio Buarque de Holanda, um sobre a influência do positivismo no pensamento militar brasileiro e outro sobre o papel desempenhado pelas Forças Armadas no ocaso do Império, nos tomos que tratam do período monárquico.

Outro proeminente intelectual uspiano que se dedicou à compreensão da participação dos militares na vida política brasileira foi o professor do Departamento de Ciência Política, Oliveiros Ferreira, que além da carreira acadêmica, trabalhou no jornal O Estado de S. Paulo. Em 1964, ano do golpe, Ferreira publicou As Forças Armadas e o desafio da Revolução, onde reuniu alguns artigos escritos para o periódico da família Mesquita nos anos de 1962 e 1963. No livro, o autor retoma a tese otimista de que os militares seriam a única instituição do Estado capaz de libertar o Brasil do atraso e da corrupção. O foco da análise de Oliveiros Ferreira reside, 
portanto, no comportamento político dos militares, assim como a grande maioria dos estudos sobre a instituição militar produzidos no país durante a ditadura. Mas o autor também avançou no estudo de outros temas relativos à Defesa, que até então mereciam pouquíssima atenção da academia.

Neste sentido, precisamos recuperar uma outra característica marcante do período em que os Estudos de Defesa começaram a se configurar no Brasil, qual seja, o insulamento burocrático de temas como geopolítica, estratégia e política externa nas Escolas Militares, na Escola Superior de Guerra (ESG) e no Itamaraty. Uma iniciativa que tentou romper este insulamento e trazer a discussão sobre assuntos estratégicos para um público mais amplo foi o Seminário Internacional Política e Estratégia promovido pela Convívio - Sociedade Brasileira de Cultura em São Paulo, em 1979, e organizado pelo professor Oliveiros Ferreira e pelo general Meira Mattos.

A agenda do evento, realizado já no período de distensão do regime militar, visava promover a aproximação entre civis e militares para a discussão de temas relativos à defesa nacional e incluía a seguinte pauta para análise: a participação do Brasil no sistema internacional; a influência da geopolítica na formação da política internacional; a estratégia das grandes potências; e o pensamento militar.

Os resultados deste seminário foram publicados posteriormente na revista Política e Estratégia que teve sua primeira edição em 1983 e circulou até 1990, sendo, neste período, a única publicação acadêmica voltada para os temas de defesa produzida fora dos quartéis. Outra iniciativa pioneira da Sociedade Convívio foi a criação de um Centro de Estudos Estratégicos em 1983, no mesmo ano em que foi editado o primeiro número da Política e Estratégia. ${ }^{2}$ No Rio de Janeiro, por seu turno, a criação do Instituto Universitário de Pesquisas do Rio de Janeiro (IUPERJ), em 1969, na Universidade Cândido Mendes, representou um passo importante para a consolidação e autonomização da Ciência Política no Brasil. Formado sobre forte influência americana, o IUPERJ trazia para a academia brasileira uma reflexão sobre o papel dos atores políticos nos processos de mudança social que se afastava substancialmente dos modelos explicativos do estruturalismo francês e do marxismo. No que concerne à discussão teórica sobre a participação dos militares na vida política brasileira, esta abordagem contribuiu para a elaboração dos primeiros estudos que analisavam o comportamento das Forças Armadas com base na dinâmica interna da própria instituição.

Ainda sobre as contribuições da então nascente área de Ciência Política no Brasil para os estudos sobre a instituição militar, devemos ter em mente que esta disciplina consolidou-se no país a partir da criação de Programas de Pós-Graduação, cujos recursos humanos foram formados, em grande 
parte, no exterior, em decorrência da política de ensino superior da ditadura e da conjuntura política de repressão, que forçou o exílio de intelectuais e militantes que se opunham ao regime de exceção instaurado no país desde 1964.

No caso específico dos Estudos de Defesa, os estudantes de pós-graduação se beneficiaram significativamente dos convênios internacionais estabelecidos pelo governo brasileiro, especialmente com a França e os Estados Unidos. Estes convênios internacionais permitiram que jovens pesquisadores brasileiros fossem estudar as Forças Armadas fora do Brasil, e este distanciamento do momento político que nós vivíamos foi fundamental para o futuro da produção acadêmica no campo. Primeiro porque estes estudantes passaram a conhecer novas técnicas de pesquisa e tomaram contato com uma discussão teórica que lhes possibilitou pensar a questão da Defesa para além da questão do regime militar no Brasil.

Além disso, cabe lembrar que durante a ditadura o acesso às fontes de pesquisa para se produzir sobre Defesa era muito restrito, e de maneira geral os estrangeiros denominados brazilianistas eram mais bem sucedidos do que os brasileiros na coleta de dados sobre as Forças Armadas. Neste contexto, produzir teses sobre os militares brasileiros fora do Brasil tornou-se a alternativa mais viável para a pequena comunidade acadêmica que tinha interesse neste objeto de estudo.

Os estudantes brasileiros que foram para a França, por meio de acordos de cooperação internacional ou forçados pelo exílio, reuniram-se em torno do professor Alain Rouquié, um especialista em América Latina que estudava o papel dos militares na formação dos Estados na região. Rouquié propunha uma nova leitura sobre o poder militar no Brasil que se afastasse da concepção instrumental, ou seja, da concepção segunda a qual as Forças Armadas seriam um instrumento de classe. Em sua visão, o Exército era um espelho das tensões da sociedade, mas um espelho deformador, uma vez que as tensões sociais que adentravam os quartéis eram absorvidas e refratadas pelo prisma institucional militar (Rouquié, 1980, p. 20). A pesquisa de Manuel Domingos Neto, sobre a presença militar francesa no Brasil no início do século XX, e de Eliézer Rizzo de Oliveira, sobre o processo decisório durante o governo Geisel, são bastante representativas das preocupações teóricas e metodológicas do grupo de acadêmicos que fizeram sua formação doutoral na França. ${ }^{3}$ Os Estados Unidos foi o outro destino dos estudantes de Ciência Política na década de 1970. Nas universidades norte-americanas, os jovens pesquisadores tiveram contato com a promissora área de sociologia militar, que tinha então como principal expoente Morris Janowitz, autor de clássicos como $O$ soldado profissional: um estudo social 
e político (1967). O cientista político Alexandre Barros foi seu aluno em Chicago e sua tese sobre a socialização profissional e atuação política dos militares brasileiros foi escrita sob a influência da perspectiva organizacional do sociólogo estadunidense.

Dois outros pesquisadores que estudaram nos EUA e produziram estudos seminais sobre as Forças Armadas Brasileiras a partir de uma perspectiva organizacional foram José Murilo de Carvalho e Edmundo Campos Coelho, que após retornarem ao Brasil se radicaram no IUPERJ. Carvalho publicou um capítulo sobre o papel político dos militares brasileiros na Primeira República na prestigiosa coleção História Geral da Civilização Brasileira, em 1977. No ano anterior, Edmundo Campos Coelho publicou seu livro Em busca de identidade: militares e política no Brasil.

\section{A NOVA REPÚBLICA, O FIM DA GUERRA FRIA E A ESTRUTURAÇÃO DO CAMPO DA DEFESA}

A década de 1980 foi marcada por um processo de redemocratização na América Latina e em outras partes do mundo, no esteio do que se convencionou chamar de Terceira Onda de democratização (Huntington, 1994). Assim como as intervenções militares das décadas de 1960 e 1970, os processos de redemocratização dos anos 1980 estiveram no centro da agenda de pesquisa dos cientistas sociais. Cabe destacar que a 'transitologia' constituía neste período uma importante área de estudos da Ciência Política, tendo contribuído para o desenvolvimento teórico e metodológico da disciplina nos seus principais centros produtores de conhecimento. ${ }^{4} \mathrm{O}$ foco do interesse nas Forças Armadas residia então na possibilidade ou não de os militares virem a ameaçar a estabilidade dos novos regimes democráticos.

No Brasil, o falecimento do presidente eleito no Colégio Eleitoral, Tancredo Neves, e a posse do então vice-presidente José Sarney - afiançada pelo novo ministro do Exército, Leônidas Pires Gonçalves -, deram início à chamada Nova República que dependeu em larga medida do aval dos militares para se manter em uma fórmula que ficou conhecida como tutela militar. $^{5}$

Na década de 1990, com o fortalecimento do Parlamento no período pós-ditatorial, entre as mudanças institucionais que influenciaram o padrão das relações civis-militares destacamos a fusão das Comissões de Relações Exteriores e Defesa Nacional na Câmara dos Deputados, ${ }^{6}$ que resultou na criação da Comissão de Relações Exteriores e de Defesa Nacional $(\mathrm{CREDN}),{ }^{7}$ a promulgação da primeira versão da Política de Defesa Nacional (PDN) em 1996, além da criação do Ministério da Defesa já no final da década, em 1999. 
Retrocedendo na digressão histórica, na academia brasileira a década de 1980 foi marcada pela volta dos pesquisadores que foram estudar os militares fora do país por força do golpe ou de acordos de cooperação. Estes acadêmicos ingressaram nas universidades, criaram linhas pesquisa, formaram novos mestres e doutores e alguns deles criaram os primeiros núcleos de pesquisa dedicados aos Estudos de Defesa.

Neste novo contexto foram criados dois núcleos voltados para o estudo de assuntos relativos à defesa no estado de São Paulo: o Núcleo de Estudos Estratégicos (NEE) na Unicamp e o Núcleo de Análise Interdisciplinar de Políticas Públicas e Estratégia (NAIPPE) na USP.

O seminal NEE foi fundado em 1985 por um grupo de pesquisadores bastante eclético que tinha uma agenda de pesquisa que cobria temas que iam das relações dos militares com o sistema político às mudanças na agenda de segurança internacional. Entre os pesquisadores que participaram da criação do Núcleo de Estudos Estratégicos, destacamos a participação de Eliézer Rizzo de Oliveira, já citado anteriormente, que desenvolveu no Núcleo dois projetos de pesquisa bastante importantes na década de 1990, um que tratou do papel do Poder Legislativo nas questões atinentes às Forças Armadas e outro que analisou o processo de criação do Ministério da Defesa. O coronel Geraldo Cavagnari, um militar da reserva, que em uma atitude então inédita foi contratado como pesquisador pela Unicamp, dedicou-se ao estudo do pensamento estratégico brasileiro, tendo atuado também como consultor do Partido dos Trabalhadores (PT) para temas relativos às Forças Armadas brasileiras. Já Shiguenoli Miyamoto, um dos primeiros civis a realizar um estudo sistemático sobre o pensamento geopolítico brasileiro, também desenvolveu projetos voltados para a análise da política externa brasileira e os impactos da globalização para as relações internacionais. Finalmente, vale destacar a atuação de João Quartim de Moraes, filósofo e militante comunista, que desenvolveu um original projeto sobre os militares brasileiros de esquerda.

No NAIPPE, criado em 1991, o professor Braz Araújo ensaiou uma primeira tentativa de inserir os assuntos de defesa na agenda das políticas públicas. Havia também no Núcleo de Análise Interdisciplinar de Políticas Públicas e Estratégia uma linha de pesquisa voltada para o estudo da história militar. Hoje o NAIPPE se mantém ativo, mas dedicado a temáticas de ações públicas nas áreas de gestão, saúde, educação, energia e transporte.

Ainda em São Paulo, a partir dos esforços do professor João Roberto Martins Filho, temos a implantação, com início em 1996, do Arquivo de Política Militar Ana Lagôa (AAL) na Universidade Federal de São Carlos (UFSCar), originalmente surgido com farta documentação cobrindo o período do regime militar, e posteriormente ampliado para também abranger material sobre assuntos estratégicos e militares em geral. 
No Rio de Janeiro, em 1986, os professores René Dreifuss ${ }^{8}$ e Eurico de Lima Figueiredo - nas figuras de, respectivamente, coordenadores executivo e adjunto - criaram o Núcleo de Estudos Estratégicos (NEST) na Universidade Federal Fluminense (UFF). Vale sublinhar que estes dois pesquisadores estudaram no Reino Unido na década de 1970 (Escócia e Inglaterra, nessa ordem), e de lá trouxeram uma perspectiva britânica dos estudos estratégicos. O NEST teve um funcionamento limitado mas serviu de embrião para a criação, neste século XXI, do Programa de Pós-Graduação em Estudos Estratégicos da Defesa e da Segurança (PPGEST) e, já na segunda década dos anos 2000, do Instituto de Estudos Estratégicos (INEST-UFF).

Outra iniciativa importante ocorrida no Rio de Janeiro na década de 1990 foi capitaneada pelo Centro de Pesquisa e Documentação de História Contemporânea do Brasil (CPDOC) da Fundação Getúlio Vargas (FGV) que, a partir de um projeto de história oral que entrevistou figuras-chave do regime militar, publicou uma série de oito livros sobre os militares do golpe de 1964 à Nova República.

Por fim, também destacamos a criação do Grupo de Estudos Estratégicos (GEE), em 1991, pelo professor Domício Proença Júnior, no Instituto Alberto Luiz Coimbra de Pós-Graduação e Pesquisa de Engenharia (COPPE) da Universidade Federal do Rio de Janeiro (UFRJ), focado na adequação dos meios militares aos objetivos políticos do Estado.

Ao longo da década de 1990, os esforços iniciais realizados na década anterior pela geração dos pioneiros nos Estudos de Defesa começaram a surtir efeito. Um conjunto maior de pesquisadores já formados no Brasil e com novas preocupações teóricas e metodológicas ingressaram nos Programas de Pós-Graduação em Ciências Humanas e a agenda de pesquisa sobre as Forças Armadas começou a se dinamizar, passando a explorar outros aspectos da instituição, além de agregar pesquisadores em diferentes estágios de formação (da iniciação científica ao pós-doutoramento).

Datam da década de 1990 as primeiras publicações de etnografias realizadas sobre Escolas Militares. Em 1990, Celso Castro publicou sua dissertação de mestrado, O espírito militar: um antropólogo na caserna (1990), narrando a pesquisa de campo realizada três anos antes na Academia das Agulhas Negras. Já no final da década, Piero Leirner publicou sua experiência de pesquisa na Escola de Comando e Estado-Maior do Exército (ECEME), Meia volta-volver: um estudo antropológico sobre a hierarquia militar (1997). A reinserção dos militares no regime democrático continuou a mobilizar a comunidade de estudiosos de Defesa e o debate sobre o nível e o tipo de autonomia que os militares mantinham em relação ao sistema político se estendeu durante toda a década. Em relação 
a este tópico os analistas brasileiros e estrangeiros ${ }^{9}$ se dividiam entre os que identificavam na manutenção de prerrogativas militares uma ameaça latente à democracia brasileira, os que identificavam avanços na direção política sobre as Forças Armadas (apesar da manutenção das prerrogativas militares), e a visão mais otimista, preconizada por Wendy Hunter (1997), segundo a qual os militares brasileiros estariam perdendo progressivamente sua influência política devido a ampliação das regras e normas inerentes à democracia.

Outro tema que despertou o interesse dos pesquisadores na década de 1990 foi a paulatina mudança de foco nas preocupações estratégicas brasileiras das fronteiras ao sul do país para as fronteiras amazônicas ao norte (MARQUES, 2003). Esta mudança de percepção de ameaça impulsionou dois conjuntos de análises sobre a questão. Por um lado, o arrefecimento das rivalidades estratégicas com a Argentina e o processo de aproximação com o vizinho platino inaugurou uma linha de pesquisa dedicada à análise do relacionamento entre os países em matéria de segurança e defesa, suas especificidades e possiblidades de cooperação. A importância atribuída pelos militares brasileiros às fronteiras norte, ou mais especificamente à Amazônia, também inaugurou uma importante linha de pesquisa caracterizada por sua pluralidade disciplinar, que reúne trabalhos da História, Antropologia, Sociologia, Geografia, Ciência Política e Relações Internacionais. O contexto político e social das fronteiras amazônicas também suscitou o debate sobre a natureza das ameaças percebidas na região, em larga medida apresentadas sob a rubrica de "novas ameaças", das ameaças não estatais à segurança do Estado, ocupando um espaço importante nas reflexões sobre as questões de segurança e defesa no Brasil e na América do Sul. Cabe destacar que os temas acima listados ainda são parte relevante da atual agenda de investigação no campo de Estudos de Defesa.

\section{DEFESA NACIONAL NO SÉCULO XXI}

O novo século tem sido auspicioso para os Estudos de Defesa no Brasil. Além da estruturação de uma pequena comunidade epistêmica que trabalha com o tema, que foi se formando nas universidades brasileiras ao longo da década de 1990, um conjunto de iniciativas governamentais propiciou que os temas relativos à defesa nacional passassem a ter mais visibilidade.

No que concerne ao arcabouço institucional, os anos 2000 marcam a estruturação do Ministério da Defesa, a revisão da Política de Defesa Nacional (2005) e a criação da Estratégia Nacional de Defesa (2008). Na segunda década do século, além da revisão da Política de Defesa Nacional (PDN), agora denominada Política Nacional de Defesa (PND), e da Estratégia 
Nacional de Defesa (END) em 2012, veio a público nesse mesmo ano a primeira versão do Livro Branco de Defesa Nacional (LBDN). No âmbito regional, a criação do Conselho de Defesa Sul-Americano (CDS) no interior da União das Nações Sul-Americanas (UNASUL) reflete o novo patamar ocupado pelas questões atinentes à defesa nacional em nossa sub-região.

$\mathrm{Na}$ academia brasileira, a partir dos anos 2000 começam a surgir os primeiros Programas de Pós-Graduação com área de concentração em Defesa. O Programa de Relações Internacionais San Tiago Dantas foi criado em 2003 a partir da associação de três universidades paulistas: a Unesp, a Unicamp e a PUC-SP, e conta com uma área de concentração em Paz, Defesa e Segurança Internacional e cursos em nível de mestrado e doutorado. Em 2008, começou a funcionar na UFF o Programa de Pós-Graduação em Estudos Estratégicos da Defesa e da Segurança que conta com um curso de mestrado e mais recentemente, em 201 1, o Programa de Pós-Graduação em Estudos Estratégicos Internacionais passou a oferecer cursos de mestrado e doutorado na Universidade Federal do Rio Grande do Sul (UFRGS).

Em 2010, os Estudos de Defesa ganham o primeiro curso de graduação na área: o Bacharelado em Defesa e Gestão Estratégica Internacional na UFRJ, um curso de natureza interdisciplinar que foi criado a partir da associação do Núcleo de Estudos Internacionais, do Instituto de Pós-Graduação e Pesquisa em Administração e do Instituto de Estudos em Saúde Coletiva.

Outro aspecto a destacar na segunda década do século XXI é a decisão das Escolas Militares de Comando e Estado-Maior das três Forças de submeter propostas de Programas de Pós-Graduação em nível de mestrado à avaliação do Ministério da Educação. Em 2012, a Escola de Comando e Estado-Maior do Exército obteve a autorização da Coordenação de Aperfeiçoamento de Pessoal de Nível Superior (Capes) para o funcionamento de seu mestrado acadêmico. No mesmo ano a Universidade da Força Aérea (Unifa) iniciou seu mestrado profissional em Ciências Aeroespaciais e, por fim, em 2013, a Escola de Guerra Naval (EGN) teve seu mestrado profissional em Estudos Marítimos recomendado.

A criação destes Programas de Pós-Graduação nas Escolas Militares, vale recordar, foi induzida em parte com recursos disponibilizados pelas agências de fomento governamentais por meio de programas como o Pró-Defesa (Capes e Ministério da Defesa) e o Pró-Estratégia (Capes e Secretaria de Assuntos Estratégicos da Presidência da República), já que ambas as propostas de financiamento se caracterizam pelo estímulo à parceria entre universidades e escolas militares. Também graças a estes dois programas de fomento foram criados centros e linhas de pesquisa voltados para os Estudos de Defesa em todo país, matizando a alta con- 
centração de recursos humanos e pesquisas do eixo Rio-São Paulo. Não menos importante, temos uma inserção dos Estudos de Defesa nos principais Programas de Pós-Graduação na grande área de Ciência Política e Relações Internacionais.

Este último ponto possui um duplo significado que merece ser exposto. Por exigir uma nota mínima para os Programas de Pós-Graduação que coordenarão o projeto interinstitucional, nota cinco para concorrer ao Edital Pró-Estratégia e nota quatro para concorrer ao Edital Pró-Defesa, estes editais "forçaram" a associação entre instituições já consolidadas e Programas de Pós-Graduação, centros, núcleos e laboratórios de pesquisa ainda em fase de estruturação, que representam a grande maioria da ainda pequena comunidade epistêmica de Estudos de Defesa. ${ }^{10} \mathrm{Se}$, por um lado, este movimento é positivo porque estimula a alocação de recursos humanos altamente qualificados das principais universidades brasileiras para o desenvolvimento de pesquisas no campo, por outro, esta exigência de pontuação mínima impede a alocação direta de recursos financeiros para a maioria dos Programas de Pós-Graduação, centros, núcleos e laboratórios de pesquisa vocacionados para os estudos atinentes à defesa, ${ }^{11}$ perpetuando um relação de "dependência acadêmica" nada salutar para o desenvolvimento de nosso campo de estudos.

Em 2005, a nascente comunidade epistêmica de Estudos de Defesa começou a se articular formalmente com a criação da Associação Brasileira de Estudos de Defesa (ABED), a partir de um desdobramento do Grupo de Trabalho Forças Armadas e Sociedade da ANPOCS. A ABED realizou seu primeiro encontro anual em 2007 na Universidade Federal de São Carlos. Desde então podemos observar um aumento significativo de pesquisadores dedicados aos Estudos de Defesa e a sedimentação de uma agenda de pesquisa com características próprias. No espaço de uma década, o processo de formação de estudiosos de Defesa deixou de ser fortemente verticalizado e centralizado na região sudeste e passou a ser mais horizontal e descentralizado, com a criação de linhas de pesquisa por todo o país.

No que tange à agenda de pesquisa em Defesa no século XXI, verifica-se uma crescente dinamização tanto do conjunto de temas tratados quanto das abordagens disciplinares, teóricas e metodológicas a partir das quais os estudos são realizados. Os novos marcos legais para o setor de defesa no Brasil, representados pela Política Nacional de Defesa, Estratégia Nacional de Defesa e Livro Branco de Defesa Nacional, bem como o processo de aproximação dos países sul-americanos em matéria de segurança e defesa e, mais recentemente, a ampliação da participação do Brasil em missões de paz sob o mandato das Nações Unidas, explicitaram a necessidade de se pensar o aparelho militar como um instrumento do Estado que desempenha um papel relevante para a inserção internacional brasileira, 
engendrando um processo que Héctor Luis Saint-Pierre denominou "revolução copernicana” nos Estudos de Defesa (Saint-Pierre, 2013).

Sem ter a pretensão de esgotar os temas abarcados pelos Estudos de Defesa na contemporaneidade, cabe registrar que a agenda de pesquisa do campo hoje difere substantivamente, em abrangência e profundidade, da discussão sobre o comportamento político dos militares que inaugurou os primeiros estudos listados neste artigo. A falta de coordenação entre as burocracias responsáveis pela face externa do Estado brasileiro, a adequação, ou melhor, a não adequação dos meios militares aos objetivos traçados nos documentos governamentais para setor de defesa, a delimitação do entorno estratégico brasileiro, as percepções de ameaças ao patrimônio nacional e à sociedade, qual a melhor forma de se contrapor a estas ameaças, qual a influência das tecnologias no setor militar, as características do parque industrial de defesa, uma reflexão mais estruturada sobre as possíveis mudanças ou não na natureza da guerra, as especificidades organizacionais das três Forças Armadas, questões relacionadas ao sistema educacional militar, gênero e família entre outras, são hoje parte da agenda que pesquisa da comunidade epistêmica de Estudos de Defesa.

\section{UMA BREVE CONCLUSÃO E ALGUNS APONTAMENTOS PARA O FUTURO DO CAMPO DE ESTUDOS}

Os Estudos de Defesa no Brasil vêm ganhando importância acadêmica e visibilidade desde a última década. A criação da Associação Brasileira de Estudos de Defesa representou um passo decisivo para que este processo se dê de forma sustentada. A incorporação de uma nova geração de estudiosos e a dinamização da agenda de pesquisa do campo mostram o vigor de uma área emergente e em expansão no Brasil. Ao olhar retrospectivamente para um contex to político e acadêmico não tão distante, procuramos identificar os fundamentos do campo de estudos ora denominado Defesa. Inaugurado em um período histórico bastante adverso para o tratamento de um tema que desperta - por sua natureza - reações apaixonadas daqueles que não têm por profissão traduzi-lo e analisá-lo com a objetividade científica possível, os Estudos de Defesa foram se desenvolvendo paulatinamente à medida em que a conjuntura política do país e o processo de institucionalização do setor de defesa foram exigindo uma reflexão qualificada sobre as questões que a realidade colocava.

No entanto, é possível verificar a partir da agenda de pesquisa mais recente a configuração de um campo de estudos que tem potencial para ir além da análise de temas suscitados pela conjuntura política. Este é o desafio que devemos enfrentar para garantir a sobrevivência e a consolidação dos Estudos 
de Defesa no Brasil. Por tratar-se de um campo que é capaz de dar respostas, senão satisfatórias, ao menos objetivas, aos formuladores de políticas públicas, criou-se uma dinâmica onde os formuladores de política tendem a acorrer à comunidade acadêmica em busca de subsídios para tratamento de temas com os quais estão trabalhando, e a comunidade acadêmica procura subterfúgios para se adequar às demandas dos formuladores de política e, ainda assim, preservar seus interesses de pesquisa. $\mathrm{O}$ formato dos editais específicos para a área de Defesa que citamos neste artigo são bastante representativos desta dinâmica.

Acreditamos que a comunidade epistêmica de Estudos de Defesa deva agir de forma a encontrar um equilíbrio entre o atendimento às demandas dos formuladores de política e a garantia de um espaço para o desenvolvimento de pesquisas históricas, teóricas e metodológicas que não dialogam com a dinâmica da conjuntura política, mas são fundamentais para a consolidação do campo. Apenas olhando além da conjuntura poderemos contribuir para uma reflexão qualificada sobre os temas com os quais teremos que lidar no futuro. Eis o desafio colocado para os próximos lustros.

\section{REFERÊNCIAS}

CARVAlHO, J. M. de. As Forças Armadas na Primeira República: o poder desestabilizador. In: FAUSTO, B. (Org.). História geral da civilização brasileira. Tomo III: O Brasil republicano, sociedade e instituições (1889 -1930). 2. vol. Rio de Janeiro/São Paulo: Difel, 1977.

CASTRO, C. O espírito militar: um antropólogo na caserna. Rio de Janeiro: Zahar, 1990.

COELHO, E. C. Em busca de identidade: o exército e a política na sociedade brasileira. Rio de Janeiro: Forense Universitária, 1976.

DANTAS, S. T. Dois momentos de Rui Barbosa. Rio de Janeiro: Casa de Rui Barbosa, 1949.

DREIFUSS, R. A. 1964: A conquista do Estado, ação política, poder e golpe de classe. Petrópolis: Vozes, 1981.

FERREIRA, O. As Forças Armadas e o desafio da Revolução. Rio de Janeiro: Edições GRD, 1964.

FUCCILLE, L. A. National defense in the brazilian legislative agenda: a critical balance. Security and Defense Studies Review, n. 6, p. 181-195, 2006.

HOLANDA, S. B. de. Da maçonaria ao positivismo. In: HOLANDA, S. B. de. História geral da civilização brasileira. Tomo II: O Brasil monárquico, do Império a República. 2. ed. 5. vol. Rio de Janeiro: Difel, 1977. 
A fronda pretoriana. In: HOLANDA, S. B. de. História geral da civilização brasileira. Tomo II: O Brasil monárquico, do Império a República. 2. ed. 5. vol. Rio de Janeiro: Difel, 1977.

HUNTER, W. Eroding military influence in Brazil: politicians against soldiers. Chapel Hill: University of North Carolina Press, 1997.

HUNTINGTON, S. P. A terceira onda: a democratização no final do século XX. São Paulo: Editora Ática S. A., 1994.

JANOWITZ, M. O soldado profissional: estudo social e político. Rio de Janeiro: Edições GRD, 1967.

LEIRNER, P. de C. Meia volta-volver: um estudo antropológico sobre a hierarquia militar. Rio de Janeiro: Editora FGV, 1997.

MARQUES, A. A. Concepções estratégicas brasileiras no contexto internacional do pós-guerra fria. Revista de Sociologia e Política, n. 20, p. 69-85, jun. 2003.

MIYAMOTO, S. Os Estudos Estratégicos e a academia brasileira: uma avaliação. Research and Education in Defense and Security Studies, 22-25 maio 2001, Center for Hemispheric Defense Studies, Washington.

MORAES, J. Q. de (Org.). A tutela militar. São Paulo: Editora Revista dos Tribunais Ltda., 1987.

O'DONNELL, G.; SCHMITTER, P. (Ed.). Transitions from authoritarian rule: tentative conclusions about uncertain democracies. Baltimore: The Johns Hopkins University Press, 1986.

OLIVEIRA, E. R. de. (Org.). Militares: pensamento e ação política. Campinas: Editora Papirus, 1987.

PION-BERLIN, D. (Ed.). Civil-Military relations in Latin America. Chapel Hill: University of North Carolina Press, 2001.

ROUQUIÉ, A. (Org.). Os partidos militares no Brasil. Rio de Janeiro: Record, 1980.

Saint-Pierre, H. L. Pensamento em Defesa no Brasil em perspectiva filosófica e histórica. In: MONTEIRO, Á. D.; WINAND, É. C. A.; GOLDONI, L. R. F. Pensamento Brasileiro em Defesa. VI ENABED. Aracaju: Editora UFS, 2013.

SODRÉ, N. W. História militar do Brasil. Rio de Janeiro: Civilização Brasileira, 1969. 


\section{NOTAS}

1. Essa tese de San Tiago Dantas, em Dois Momentos de Rui Barbosa (1949), foi posteriormente endossada por autores como Nelson Werneck Sodré, em sua História Militar do Brasil (1965).

2. Na apresentação do primeiro número da revista Política e Estratégia (1983), o jornalista Antonio Carlos Pereira expõe os propósitos do periódico e do Centro de Estudos Estratégicos da Convívio. O histórico destas atividades foi recuperado a partir do artigo do professor Shiguenoli Miyamoto, Os Estudos Estratégicos e a Academia Brasileira: Uma Avaliação, escrito em 2001 . Além das atividades patrocinadas pela Convívio, Miyamoto aponta outros três grandes acontecimentos que marcaram a inserção da universidade brasileira ou de professores individualmente em assuntos de defesa: 1) a criação do Núcleo de Estudos Estratégicos da Unicamp e de sua revista, a Premissas; 2) os Simpósios de Estudos Estratégicos Argentino-Brasileiros, organizados pelos Estados Maiores dos dois países. Este Simpósio foi realizado em Buenos Aires em sua primeira versão, em 1987, e em São Paulo no ano subsequente. Os resultados desses eventos foram publicados na Política e Estratégia; 3) as primeiras edições dos Encontros Nacionais de Estudos Estratégicos que tiveram lugar em Brasília (1994), São Paulo (1995), Rio de Janeiro (1996) e Campinas (1998). Ressaltamos que o artigo de Miyamoto é o primeiro esforço de sistematização da trajetória do campo de Defesa no Brasil e seu autor é uma referência importante para nossa comunidade epistêmica.

3. Os resultados das pesquisas de Eliézer Rizzo de Oliveira e Manuel Domingos Neto foram publicados no livro organizado por Alain Rouquié, Os partidos militares no Brasil (1980).

4. Entre os trabalhos de maior repercussão nesta área de estudos destaca-se o livro organizado Guilhermo O'Donnell e Philippe Schmitter, Transitions from Authoritarian Rule: Tentative Conclusions about Uncertain Democracies (1986).

5. "A tutela corresponde a uma manifestação específica do papel militar na preservação da ordem social num momento em que a corporação castrense não se encontra no exercício do poder de Estado, sem no entanto haver perdido a importância orgânica no conjunto dos órgãos do Estado" (OLIVEIRA, 1987, p. 61).

6. A dificuldade em se preencher os cargos desta última - lembrando que cada parlamentar só pode ter assento como titular em uma única Comissão - fez com que os parlamentares abrissem num primeiro momento uma exceção, permitindo que os deputados membros da 
Comissão de Defesa Nacional pudessem fazer parte de uma segunda Comissão. Mais à frente, dando-se conta do equívoco que tal posicionamento acarretava e procurando valorizar institucionalmente o tema defesa nacional na Casa, os legisladores optaram por resgatar a norma de um deputado por Comissão e por fundi-la com a Comissão de Relações Exteriores, haja vista que, em tese, ambas tratavam de assuntos afins. Para maiores detalhes, ver Fuccille (2006).

7. A mesma Comissão no Senado - CRE - tende a atuar quase que exclusivamente no campo das relações internacionais, sancionando a nomeação de embaixadores, apreciando matérias referentes a comércio exterior, assuntos ligados a organismos multilaterais, etc.

8. Vale destacar que René Dreyfuss havia publicado alguns anos antes o prestigioso livro 1964: A Conquista do Estado (1981), uma das principais referências acerca do golpe militar.

9. Uma coletânea que contempla visões diferentes sobre as relações civis-militares no Brasil durante a década de 1990 foi organizada por Pion-Berlin em 2001 em Civil-Military Relations in Latin America.

10. Recentemente esta postura foi reiterada por meio do Programa Álvaro Alberto de Indução à Pesquisa em Segurança Internacional e Defesa Nacional, financiado pelo CNPq e Ministério da Defesa, que exigiu que as propostas fossem apresentadas por pesquisadores vinculados a programas de pós-graduação com nota quatro ou superior.

11. A descentralização dos recursos financeiros de cada projeto aprovado nestes editais deve ser pactuada pela equipe proponente do projeto. 
ENSINO E PESQUISA EM DEFESA NO BRASIL:

ESTRUTURAÇÃO DO CAMPO E DESAFIOS"

\section{RESUMO}

Neste artigo iremos delinear a trajetória dos Estudos de Defesa no Brasil começando com um breve panorama das percepções da intelectualidade brasileira sobre as Forças Armadas - em especial dos cientistas sociais nas décadas de 1960 e 1970 -, passando então à identificação dos primeiros estudos que impulsionaram a configuração do campo e algumas iniciativas mais estruturadas que deram suporte ao seu crescimento ao longo das décadas para, em seguida, acompanharmos as mudanças estruturais nos contextos políticos internacional, regional e nacional na década de 1990 e suas conexões com o ambiente acadêmico da Ciência Política e das Relações Internacionais no Brasil. Também detalharemos a estruturação de linhas de pesquisa em Defesa nos Programas de Pós-Graduação a partir da criação de editais de fomento à pesquisa voltados especificamente para o campo e, por fim, abordaremos o processo de criação da Associação Brasileira de Estudos de Defesa (ABED) e os desafios colocados para o campo de estudos nos próximos anos.

Palavras chave: Defesa; Relações Internacionais; Ciência Política; Estudos Militares.

\section{ABSTRACT}

In this article we will outline the trajectory of Defense Studies in Brazil starting with a brief overview of the perceptions of the Brazilian academy of the Armed Forces - in particular social scientists in the 1960s and 1970s - then passing to the identification of the first studies that boosted the field configuration and some more structured initiatives that supported the growth over the decades for, then, following the structural changes in the international, regional and national political contexts in the 1990s and its connections with the academic environment of Political Science and International Relations in Brazil. We will also detail the structuring of research lines in Defense in Graduate Programs from the creation of funding announcements for research specifically focused on the field and, finally, we discuss the process of creating the Brazilian Defense Studies Association (ABED) and the challenges posed to the field of Defense Studies in the coming years.

Key-words: Defense; International Relations; Political Science; Military Studies.

Recebido em: 01/05/2016. Aprovado para publicação em: 11/05/2016. 